\title{
A Retrospective- Prospective Study for the Efficacy and Safety of Entecavir in a Cohort of West Asian with Chronic HBV Infection
}

\author{
Kafya A. Akrouf', Amal A. Gad ${ }^{1,2^{*}}$, Eman A. Ibrahim³, Mohamed F. Kassem³, \\ Fatehia M. Abdelmonem ${ }^{3}$, Naglaa E. Kholy ${ }^{3}$
}

${ }^{1}$ Amiri Hospital, Kuwait, Thanian al Ghanem Gastrointestinal Centre, Kuwait, ${ }^{2}$ Suez Canal University School of Medicine, Internal Med. Depart. Egypt, ${ }^{3}$ Al Azhar University, Tropical Med. Depart., Egypt

\begin{abstract}
Aim: To assess the long-term efficacy and safety of Entecavir in the treatment of CHB. Patients and Methods: This study included 70 CHB consecutive patients on Entecavir for at least 36 months retrospectively, followed prospectively for 18 months. Results: twenty-three (32.8) were $\mathrm{HBeAg}+\mathrm{ve}, 47.1 \%$ naive, 22 (31.4\%) females, with a mean age of $42.9 \pm 13,14$ (20\%) cirrhotic and $1(1.4 \%)$ decompensated. There were no significant differences in the pre- treatment HBVDNA level among HBeAg (+ve) and HBeAg-ve group, with a mean \pm SD log 10 of $7.9 \pm 5.4$ and $7.4 \pm 5.0$ respectively. $(P=0.237)$. There was a significant viral load reduction after 6 months Entecavir therapy that was more in the $\mathrm{HBeAg}$-ve compared to $\mathrm{HBeAg}+\mathrm{ve}$ group. In $\mathrm{HBeAg}$ +ve, $19(82.61 \%)$ had HBV-DNA suppression after a median of 7 month, compared to $100 \%$ in HBeAg -ve with a median of 5 month $(P<0.05)$. In the HBeAg-ve group; one $(2.13 \%)$ had $\mathrm{HBsAg}$ loss at 45 month compared to none in $\mathrm{HBeAg}(+\mathrm{ve})$ group $(\mathrm{P}<0.001)$, while in the HBeAg (+ve) group; 5 (21.74\%) showed HBeAg clearance after a median of 16 month. Multivariate analysis identified HBeAg negative status, as the only independent factor affecting viral suppression. The drug showed $100 \%$ safety. None showed hepatic decompensation, HCC or reported death. Conclusions: In real life data; long term Entecavir treatment effectively sup-pressed HBV. Entecavir is considered an effective and safe treatment for CHB patients compared to $82 \%$ in HBeAg (+ve) group. Entecavir is considered an effective and safe choice on long term use for treatment CHB patients.
\end{abstract}

Keywords: HBV, antigen, antibody, sero-conversion, side effects

\section{Introduction}

Hepatitis B virus (HBV) is a partially double spiral type DNA virus. Globally, approximately over 400 million individuals are infected with hepatitis B. HBV is known as one of the most important carcinogens. Every year, over one million individuals die due to HBV-related causes $^{(1)}$. It is estimated that $5 \%$ to $15 \%$ of the population are chronic carriers of hepatitis B in developing countries, whereas in North America and Western Europe only $1 \%$ of the popu- 
lation is chronically infected. Chronic HBV infection is highly prevalent in subSaharan Africa, Southeast Asia, the Eastern Mediterranean region, the Amazon basin and the Caribbean $^{(2)}$. Perinatal transmission is believed to be the most important mode in regions of developing world with high and intermediate HBV prevalence rates. HBV remains a major nosocomial pathogen in many hospitals. Transmission may occur due to unsafe injections, blood transfusions and lack of awareness of infection control. Sexual contact also accounts for some HBV transmission(3). The spectrum of disease and natural history of chronic HBV infection is diverse and variable, ranging from a low viremic inactive carrier state to progressive chronic hepatitis, which may evolve to cirrhosis and $\mathrm{HCC}^{(4)}$. Carriers of HBV are at increased risk of developing cirrhosis, hepatic decompensation and hepatocellular carcinoma (HCC). Although most carriers will not develop hepatic complications from chronic hepatitis $B$, $15 \%$ to $40 \%$ will develop serious squeal during their lifetime ${ }^{(5)}$. HBV-related end stage liver disease or HCC are responsible for over one million deaths per year and currently represent $5-10 \%$ of cases of liver transplantation ${ }^{(6)}$. Primary objective in hepatitis B treatment is to improve clinical and histological progression and to provide virus eradication. For many years, interferon, Lamivudine, Adefovir, Telbivudine, Entecavir and tenofovir still used in treatment of chronic hepatitis B. Entecavir and tenofovir are potent antiviral drugs. The treatment with these drugs leads to normalization in liver enzymes, improvement in liver histology, $\mathrm{HBsAg}$ and $\mathrm{HBeAg}$ loss and undetectable HBV DNA levels $(7,8)$. Elevation of the decreased HBV DNA during treatment is attributed to drug resistance or noncompliance ${ }^{(9)}$. Entecavir, a new guanosine nucleoside analogue with specific activity against HBV DNA poly- merase, represents a third agent within the nucleoside/nucleotide HBV polymerase inhibitor class. It has distinct advantages over Lamivudine and Adefovir Dipivoxil: it has a three-step mechanism of action, is the most potent inhibitor of HBV DNA polymerase, is not associated with any major adverse effects and has a limited potential for resistance. In clinical trials, Entecavir was superior to Lamivudine in all primary endpoints in both nucleoside-naive and Lamivudine-refractory hepatitis $\mathrm{B}$ e-antigen (HBeAg)-positive and HBeAg-negative patients ${ }^{(10)}$. Entecavir should be considered a first- or secondline treatment option for the management of HBeAg-positive or -negative nucleoside -naive or Lamivudine-refractory CHB patients ${ }^{(10)}$. This study aimed to assess the efficacy and safety of Entecavir in the treatment of chronic viral hepatitis $B$ ( $\mathrm{CHB}$ ) and to check therapeutic end points for Entecavir and its predictors in Kuwait.

\section{Material and Methods}

This is a retrospective cohort - longitudinal study to assess the efficacy and safety of Entecavir in the treatment of CHB AsianArabic patients (in Kuwait) for 54 months who were nucleosides- naïve and experienced patients, comparing $\mathrm{HBeAg}$ positive and $\mathrm{HBeAg-ve}$ subgroup. A total of $70 \mathrm{pa}-$ tients were consecutively confronted according to selection criteria (mentioned below) at Gastroenterology centers of Amiri hospital and Al Adan hospital in Kuwait between Oct 2012 and April 2014. Inclusion criteria: The following patients were included: i) Consecutively confronted adult (>18-Yr-old), ii) Kuwaity CHB patients, iii) Currently on Entecavir therapy. Exclusion criteria: The following patients were excluded: i) IgM anti-HBC positive HCV-Ab positive, HDV Ab positive; ii) HCC patients, iii) post-transplanted patients. Entecavir dosing: was decided according 
to APASL 2012 with dose modification according to renal function. In those with normal renal function; naïve patients received $0.5 \mathrm{mg}$ while experienced ones received $1 \mathrm{mg}$ daily dose $\mathrm{e}^{(10,11)}$.

HCC diagnosis: based on either histopathology, Tri-phasic CT findings and/ or S. AFP level.

End point assessment: 1) Virological response was defined as undetectable HBVDNA using branched chain DNA assay in IU /ml with HBV-DNA $<20 \mathrm{IU} / \mathrm{ml}^{(11)}$. 2) Biochemical response: was defined as ALT IAST normalization. 3) Sonographic response: was defined as improvement echogenicity, nodularity, hepatic size or signs of portal hypertension on treatment (size of portal, splenic veins and ascites). A full history was taken from all patients including socio- demographic data, other co-morbid disease(s), current drug history, previous HBV treatment, drug adherence to treatment. Possible side effects of the Entecavir were checked every 3-6 month. A thorough clinical examination was performed to all patients to detect signs of liver cirrhosis and hepatic decompensation or evidence of other organ system affection.

Biochemical assessment: this was carried out_every 3-6 months and includes; platelet count, (Normal range 150-410 109/L), INR, (Normal range up to 1.2), Fasting Blood Sugar (Normal range 3.9-6.1mmol. /L), ALT, (range 10-60lU/L), AST (range 1042IU/L), total S. bilirubin (range 3-25umol. /L), S. albumin. (range $35-48 \mathrm{~g} / \mathrm{L}$ ), BUN (range 2.5-7.1mmol. /L), S. creatinine (range 62-115umol/L). Reference for FBS, LFT and RFT is quoted from manufacture documentation in the leaflets and user manual guides the machine used is Beckman Coulter instruments DXC 800).

Virological assessment: this was carried out every 3-6 month for HBsAg, HBsAb, $\mathrm{HBeAg}, \mathrm{HBeAb}$ and HBV-DNA (using quantitative $P C R$. complete viral suppression was considered at $20 \mathrm{lU} / \mathrm{ml}$, according to Kit Roche diagnostic range). Alpha fetoprotein (AFP) was also assessed every 3-6 month (normal range $2-10 \mathrm{ng} / \mathrm{ml}$ ), quoted from manufacture documentation in the leaflets and user manual guides according to the international accepted range. Conventional abdominal ultra-sonography was done using 2 apparatus of Aquson Antas/Siemens by convex curved probes equivalent to $4.1 \mathrm{MHz}$ for assessment liver cirrhosis. Cirrhosis was diagnosed if coarse texture liver or shrunken liver with either splenomegaly or portal vein diameter more than $14 \mathrm{~mm}$.

Duration of treatment: For CHB Entecavir long-term cohort, duration of treatment was defined as the total duration in months from the first dose Entecavir to the last date of dosing follow up (F/U). Assessment of Entecavir efficacy: Efficacy assessments included the following endpoints: HBV DNA $\leq 20 \mathrm{IU} / \mathrm{ml}$, HBsAg/ Ab Seroconversion and $\mathrm{HBeAg} / \mathrm{Ab}$ seroconversion ${ }^{(11)}$.

Drug safety assessment: Safety of Entecavir was assessed throughout the study period (every 3-6 month) while on treatment which included ongoing hepatic events, adverse events [headache, fatigue, dizziness, nausea, vomiting diarrhea, insomnia and hematuria], treatment discontinuation due to adverse events (mentioned before), LFT worsening on treatment (e.g. hyperbilirubinemia, or hepatic decompensation), or death while ontreatment.

Assay Methodology: Serum HBV DNA was quantified by a central laboratory (AL sahibmain capital virology lab) using PCR assay by Roche Molecular Systems, Inc. - Branchburg (lower limit of detection 20lU/mL). $\mathrm{HBV}$ serology (HBsAg, HBsAb, $\mathrm{HBeAg}$, and $\mathrm{HBeAb}$ ) were assessed using, enzyme immunoassay (Abbott Diagnostics, Germany). HBV- DNA Genotype involved PCR amplification of the HBV reverse transcriptase do- 
main, followed by nucleotide sequence analysis. (Roche diagnostic Kits).

Ethical considerations: All administrative approvals were taken before the conduction of the study. All the examined patients were informed about the aim of the study and informing them that all data were treated in confidential manner; written / oral consent was taken from every examined patient.

\section{Statistical Analyses}

All data analyses are descriptive. Tabulations by treatment groups are presented for each of the efficacy and safety variables. Continuous variables are summarized using the mean and the median values. Binary variables are summarized by counts and percentages. Efficacy endpoints were assessed among patients. Data were fed to the computer using Statistical package for Social Science (SPSS version). Simple descriptive statistics such as frequency and percentage distribution for categorical variables and mean with the standard deviation for quantitative variables were used. The median was also calculated for all scores and none normally distributed variables. For comparative purposes Chi-square and Fisher exact test (when the expected number of a cell is less than 5 in a two by two table) tests were used for categorical variables, student-t test and Mann Whitney (for discrete variables or those not normally distributed) tests for quantitative variables. For comparison between groups, analysis was initially carried out based on a series of univariate analysis comparison. In order to control simultaneously for possible confounding effect of the variables, multiple, logistic regression was used for the final analysis. In the univariate analysis, the association between exposure and outcome was expressed in terms of odds ratio (OR) together with their 95\% confidence interval $(95 \% \mathrm{Cl})$. Appropriate inferential statistics was done with level of sig- nificance of (0.05). Quality control of data was assured through double check by supervisors to assure accuracy and reliability of data.

\section{Results}

The present study included 70 Asian-Arabic adult patients with chronic hepatitis B infection referred to gastroenterology department, Thunayan Al- Ghanem center in Amiri hospital and gastroenterology department in Al-Adan hospital in Kuwait. Results showed that 23 (32.8) were HBeAg (+ve). All of them were of genotype $D, 47.1 \%$ naive, 22 (31.4\%) females, with a mean age of $42.9 \pm 13$, 14 (20\%) showed evidence of cirrhosis and one patient was (1.4\%) decompensated.

Background profile: There was no significant difference among $\mathrm{HBeAg}$ positive and negative sub-groups in their background data, except for the frequency of co-morbidities (table 1). As in HBeAg (+ve) group; 20 (87\%) had no co-morbid condition compared to 26 (55.3\%) of HBeAg-ve group ( $P=0.009)$. There was a statistically significant difference, (Table 2) in their previous NUC experience $(16,69.6 \%$ vs. $21,44.7 \%, p<0.05)$ respectively. There was no significant difference in the pre-treatment ALT, AST, S. bilirubin, S. albumin levels, INR or platelets count among the two groups (table3). In addition, no significant difference in the pretreatment ultrasonographic findings was found among the two groups (Table 4) Also, there was no significant differences in the pre-treatment HBV-DNA level (Table 5) with a mean $\pm S D \log _{10}$ of $7.9 \pm 5.4$ and $7.4 \pm 5.0$ respectively $(P=0.237)$.

Biochemical response: There was a statistically significant improvement in the mean ALT, PLT and S. albumin in HBeAg (+ve) group throughout the study period (54 months). While, there was no significant changes in LFT or PLT count in the HBeAg ve group (graph 1). 
Table 1: Comparison of background data among the studied groups

\begin{tabular}{|l|c|c|c|c|}
\hline & $\begin{array}{c}\mathrm{HBeAg}(+\mathrm{ve}) \\
\mathrm{N}=23\end{array}$ & $\begin{array}{c}\mathrm{HBeAg}(-\mathrm{ve}) \\
\mathrm{N}=47\end{array}$ & $\begin{array}{c}\text { Total) } \\
(\mathrm{n}=70)\end{array}$ & $\begin{array}{c}\mathrm{P} . \\
\text { Value }\end{array}$ \\
\hline $\begin{array}{c}\text { Age in yrs. } \\
\text { Mean ( } \pm \text { SD }) \\
\text { Range }\end{array}$ & $\begin{array}{c}37(13.42) \\
(20-77)\end{array}$ & $\begin{array}{c}48.81(12.1) \\
(23-83)\end{array}$ & $\begin{array}{c}42.9(13) \\
(20-83)\end{array}$ & 0.001 \\
\hline Female n (\%) & $6(26.1)$ & $16(34.0)$ & $22(31.4)$ & 0.501 \\
\hline Co-morbidity: n (\%) & $20(87)$ & $26(55.3)$ & $46(65.7)$ & \\
Non & $2(8.7)$ & $3(6.4)$ & $5(7.1)$ & 0.009 \\
DM & 0 & $3(6.4)$ & $3(4.3)$ & \\
HTN & $1(4.3)$ & $15(31.9)$ & $16(22.9)$ & \\
Multiple medical & & & & \\
problems & & &
\end{tabular}

Virological response: There was a statistically significant reduction in HBV viral load (Table 6 ) in the HBeAg (-ve) compared to the HBeAg (+ve) group throughout the follow up period (Graph2). In HBeAg (+ve), 19 patients (82.61\%) had complete HBV-DNA suppression after a median period of 7 month. The other 4 (17.39\%) had showed secondary non-response after

a median period of 24 mos, while in $\mathrm{HBeAg}$ -ve group; all 47 (100\%) had complete HBVDNA suppression after a median period of 5 month. Serological response: All HBeAg (+ve), patients (100\%) remained $\mathrm{HBsAg}$ positive. However, 5 of them (21.7\%) HBeAg /Ab seroconverted after a median period of 13 mos. While in $\mathrm{HBeAg}(-\mathrm{ve})$ patients, one patient $(2.13 \%)$ had $\mathrm{HBsAg} / \mathrm{Ab}$ seroconversion after $45 \mathrm{mos}$ of treatment with Entecavir. this patient was previously treated with PEGylated interferon then Lamivudine with Adefovir, but was non-responder. On Entecavir therapy; he showed complete viral suppression after 3 mos only.

Table 2: The frequency of Naïve versus experienced $\mathrm{CHB}$ patients

\begin{tabular}{|l|c|c|c|c|c|c|c|}
\hline & \multicolumn{2}{|c|}{$\begin{array}{c}\text { HBeAg (+ve) } \\
\mathrm{N}=23\end{array}$} & \multicolumn{2}{c|}{$\begin{array}{c}\text { HBeAg (-ve) } \\
\mathrm{N}=47\end{array}$} & \multicolumn{2}{c|}{ Total } & \multirow{2}{*}{ p. value } \\
\hline & $\mathrm{N}$ & $\%$ & $\mathrm{~N}$ & $\%$ & $\mathrm{~N}$ & $\%$ & \\
\hline Naïve & 7 & 30.4 & 26 & 55.3 & 33 & 47.1 & \\
\hline Experienced & 16 & 69.6 & 21 & 44.7 & 37 & 52.9 & $<0.05$ \\
\hline
\end{tabular}

*This table shows that there was statistically significance difference with regards to previous NUC exposure in the studied groups.

Sonographic response: In $\mathrm{HBeAg}$ (+ve) group; one (4.35\%) showed improvement of US detected pre-treatment (regression in hepatic size) three (13.05\%) showed regression of pre-treatment heterogeneous texture to homogenous pattern post treatment, while 6 patients (26.10\%) showed no improvement. At the Meanwhile, 17 patients (73.91\%) maintained normal hepatic texture pre-and post-treatment till the end of follow up period (54 months). In HBeAg-ve group, 2 (4.24\%) showed improvement of US de- tected pre-treatment hepatomegaly to normal sized liver post-treatment, while 4 (8.48\%) showed improvement in texture. On the other hand, 25 (53.19 maintained normal hepatic texture pre-and post-treatment till the end of follow up period (54 months). Factors associated with undetectable levels of HBV-DNA after 54 months follow up: As shown in univariate analysis (Table 7); four factors affected viral load suppression (Age, $\mathrm{P}=0.0014, \mathrm{ALT}, \mathrm{P}=0.016, \mathrm{AST}, \mathrm{P}=0.006$, HBeAg-ve, $P=0.00$ ), while in multivariate 
analysis; pretreatment hepatitis Antigen ent factor affecting viral load suppression status (HBeAg-ve) was the only independ- (OR=16.9, 95\% Cl 20.287(0.0--- $), P=0.000)$.

Table 3: Comparison of liver function, mean PLT and AFP in the studied groups pre-treatment

\begin{tabular}{|l|c|c|c|c|c|}
\hline \multirow{2}{*}{} & \multicolumn{2}{|c|}{ HBeAg (+ve) } & \multicolumn{2}{c|}{ HBeAg (-ve) } & \multirow{2}{*}{ P. Value } \\
\cline { 2 - 5 } & Mean & \pm SD & Mean & \pm SD & \\
\hline ALT (IU/L) & 51.13 & 22.82 & 47.98 & 99.37 & 0.837 \\
\hline AST (IU/L) & 38.87 & 19.63 & 44.68 & 83.86 & 0.654 \\
\hline T. BiL (Umol/L) & 21.08 & 16.48 & 17.44 & 13.58 & 0.365 \\
\hline S. Alb (g/L) & 37.91 & 4.33 & 37.63 & 10.51 & 0.875 \\
\hline PLT (109/L) & 237.04 & 67.25 & 225.34 & 66.62 & 0.496 \\
\hline INR & 1.09 & 0.15 & 1.17 & 0.57 & 0.384 \\
\hline AFP (ng/L) & 2.16 & 1.53 & 2.90 & 2.24 & 0.158 \\
\hline
\end{tabular}

*This Table shows that there was no statistically difference as regards Liver function test, PLT, and AFP in the studied groups.

Safety and adverse effects (table 7): Ontreatment symptoms: In $\mathrm{HBeAg}$ (+ve) group; 21 (91\%) were asymptomatic, one patient had fatigue (4.3\%), and one another patient (4.3\%) had fatigue, abdominal pain, jaundice and distention before treatment that did not show evidence of improvement on Entecavir therapy. In $\mathrm{HBeAg}$-ve group; 44 (93.6\%) were asymptomatic, one patient (2.1\%) had fatigue, another patient (2.1\%) had abdominal pain, and one patient (2.1\%) had both jaundice and fatigue before treatment that did not improve on Entecavir therapy. As overall; throughout treatment follow up period (54 month), 65 patients (92.9\%) from both groups were asymptomatic with no adverse hepatic events, treatment discontinuations or hepatic decompensation. No deaths reported on-treatment for a total follow up.

Table 4: HBV-DNA level and genotype in the studied groups before start of treatment

\begin{tabular}{|c|c|c|c|c|c|}
\hline & \multicolumn{2}{|c|}{$\begin{array}{c}\text { HBeAg (+ve) } \\
\quad \mathrm{N}=23\end{array}$} & \multicolumn{2}{|c|}{$\begin{array}{c}\text { HBeAg (-ve) } \\
\quad N=47\end{array}$} & \multirow{2}{*}{ p. value } \\
\hline & Mean & $\pm \mathrm{SD}$ & Mean & $\pm \mathrm{SD}$ & \\
\hline $\begin{array}{l}\text { Mean HBV DNA } \\
\text { Log } 10(\mathrm{IU} / \mathrm{ml})\end{array}$ & $7.9 \pm$ & $206,084,000.1$ & $28,774,877.94$ & $110,100,715 \cdot 5$ & 0.237 \\
\hline \multirow{2}{*}{ Genotype (D) } & $\mathrm{N}$ & $\%$ & $\mathrm{~N}$ & $\%$ & \\
\hline & 23 & 100 & 47 & 100 & \\
\hline
\end{tabular}

*This table shows that there was no statistically difference as regards HBV-DNA level in the studied groups and all patients were Genotype (D).

\section{Discussion}

Current $\mathrm{CHB}$ treatment recommendations advocate sustained suppression of HBVDNA as the primary goal of antiviral therapy. A key requirement for maintaining longterm HBV-DNA suppression is the avoidance of resistance to the antiviral(11). Patients with persistently elevated viral load are at the greatest risk of developing liver disease progression and adverse outcomes. It has also been shown that even patients with low-level HBV-DNA viremia $10^{4}$ to $10^{5} \mathrm{cop}$ ies $/ \mathrm{mL}$ ) are at risk of fibrosis, cirrhosis, and 
$\mathrm{HCC}^{(12)}$. In 2010; interferon (IFN)-based therapies (conventional IFN and peg-IFN-alpha$2 a$ or pegIFN-alpha-2b) and the nucleos ( $t$ ) ides; Lamivudine, Adefovir, Telbivudine, and Entecavir are currently recommended for the treatment of patients with hepatitis $\mathrm{B}$ eantigen ( $\mathrm{HBeAg}$ )-positive $\mathrm{CHB}^{(13)}$. For patients with $\mathrm{HBeAg}$-negative $\mathrm{CHB}$ and those with cirrhosis; nucleos(t)ide analogs with high potency and low resistance rates, such as Entecavir, are preferred. The AsianPacific consensus statement on the management of $\mathrm{CHB}$ recommends that conventional IFN or pegIFN-aza, Lamivudine, Adefovir, Entecavir, Telbivudine, and the nucleotide analogue, Tenofovir, can all be considered for initial therapy in patients without liver decompensation ${ }^{(14)}$.

Table 5: HB viral response in the studied groups after treatment

\begin{tabular}{l|c|c|c|c|c|}
\hline \multirow{2}{*}{ Marker } & \multicolumn{2}{|c|}{$\begin{array}{c}\mathrm{HBeAg}(+\mathrm{ve}) \\
\mathrm{N}=23\end{array}$} & \multicolumn{2}{c|}{$\begin{array}{c}\mathrm{HBeAg}-\mathrm{ve} \\
\mathrm{N}=47\end{array}$} & \multirow{2}{*}{$\begin{array}{c}\text { V. } \\
\text { Value }\end{array}$} \\
\cline { 2 - 5 } & $\mathrm{N}$ & $\%$ & $\mathrm{~N}$ & $\%$ & \\
\hline HBsAb seroconvert ion* & 0 & 0 & 1 & 2.13 & $<0.001$ \\
\hline HBeAb seroconvert ion** & 5 & 21.74 & - & - & \\
\hline Complete viral suppression & 19 & 82.6 & 47 & 100 & $<0.001$ \\
\hline
\end{tabular}
*ne patient from group (2) was seroconverted from HBsAg to HBsAb after 48 months of be-
ing on Entecavir. **Five patients from group (1) were seroconverted from HBeAg to HBeAb;
1 after 12 months, 3 after 15 months \& 1 after 24 months from start of treatment with
Entecavir.

According to data released by the market research firm, IMS Health, Entecavir currently accounts for $26 \%$ of the market share for HBV treatment in the People's Republic of China, compared with 39\% for Adefovir. Lamivudine and Telbivudine, account for $22 \%$ and $8 \%$ respectively of the market share $^{(15)} \cdot$ It is demonstrated that long-term Entecavir therapy in HBeAg (+ve) achieved and maintained HBV-DNA suppression. At fifth year, $94 \%$ of patients in the Entecavir long-term cohort had HBV-DNA 300 copies/ $\mathrm{ml}$. The importance of maintaining prolonged HBV-DNA suppression to avoid or minimize the long-term complications of CHBV has been recognized in several longterm studies of disease progression and outcome ${ }^{(16)}$. In our study, we were able to demonstrate Entecavir efficacy and safety in a real-world study of a cohort of Asian Arabic patients (Kuwaiti) with genotype D. For our knowledge, this is the first long term retrospective -prospective study from west Asia in this regards. However, a limited study from Saudi Arabia showed conflicting results compared to ours. It was a retro- spective study only, with a shorter follow up period (48 wks.) and smaller population, (43 patients) which makes it difficult to compare results ${ }^{(17)}$. The biochemical response to treatment in our data was rather promising; as there was significant decrease in mean ALT after 6 months of starting Entecavir from (51.13 to $35.61 \mathrm{IU} / \mathrm{L}, \mathrm{P}=0.034$ ) in the HBeAg +ve compared to (47.98 to 30.13 $\mathrm{IU} / \mathrm{L}$ ) in the $\mathrm{HBeAg}$-ve group respectively. All the studied patients showed normal ALT at the end of follow up period (54 month) with a mean of 36.74 and $26.26 \mathrm{IU} / \mathrm{L}$ in both groups respectively. Such a finding coincides with other previous studies that showed a significant reduction of the mean ALT on treatment with Entecavir(12,17-19). Similarly, jie Luo and his collages from china showed, in a retrospective study of 230 nucleos(t)ide naïve CHB patients; an ALT normalization throughout the study period ( 5 yr.) from $73.9 \%$ at first year to $100 \%$ at 5 th year of treatment ${ }^{(18)}$. Our results showed $82.61 \%$ complete HBV-DNA suppression in HBeAg (+ve), compared to $100 \%$ in HBeAgve patients. 
Table 6: Univariate and multivariate analysis of the studied groups associated with undetectable level of HBV-DNA at 54 months.

\begin{tabular}{|l|c|c|c|c|}
\hline \multirow{2}{*}{ Variables } & \multicolumn{2}{|c|}{ Univariate analysis } & \multicolumn{2}{c|}{ Multivariate analysis } \\
\cline { 2 - 5 } & OR $(95 \% \mathrm{Cl})$ & P. Value & OR $(95 \% \mathrm{Cl})$ & P. Value \\
\hline Age & $6.044(4-31-15.6)$ & 0.014 & $0.081(0.64-3.1)$ & 0.286 \\
\hline Gender & $0.081(0.54-3.2)$ & 0.837 & $0.09(0.65-3.69)$ & 0.837 \\
\hline Drug History & $0.014(0.65-3.69)$ & 0.906 & $0.162(1.35-4.97)$ & 0.480 \\
\hline Past Med. History & $0.162(1.35-4.97)$ & 0.689 & $0.072(0.53-3.1)$ & 0.469 \\
\hline ALT & $5.751(0.07-40.91)$ & 0.016 & $0.09(0.65-3.69)$ & 0.529 \\
\hline AST & $7.428(0.58-36.87)$ & 0.006 & $4.53(6.1-33.64)$ & 0.178 \\
\hline T.BiL & $2.792(0.76-9.93)$ & 0.126 & $2.681(0.73-9.82)$ & 0.126 \\
\hline S.AlB & $4.53(602-34.72)$ & 0.132 & $4.53(6.1-33.61)$ & 0.134 \\
\hline AFP & $2.123(0.27-15.97)$ & 0.699 & $2.134(0.25-14.84)$ & 0.699 \\
\hline U/S Finding & $3.372(0.69-13.58)$ & 0.066 & $4.43(6.2-30.65)$ & 0.217 \\
\hline Seroconversion & $0.398(0.176-1.46)$ & 0.528 & $0.287(0.165-1.34)$ & 0.512 \\
\hline HBeAg negative & $16.5(0.0--\infty)$ & 0.000 & $20.287(0.0---\infty)$ & 0.000 \\
\hline
\end{tabular}

* In Univariate analysis 4 factors affected HBV viral load suppression, while in multivariate analysis the only independent factor was HBeAg -ve.

Table 7: Frequency of occurrence of different symptoms during Entecavir therapy

\begin{tabular}{|l|c|c|c|c|c|c|c|}
\hline & \multicolumn{2}{|c|}{$\begin{array}{c}\text { Group (1) } \\
\text { HBeAg (+ve) } \\
\mathrm{N}=23\end{array}$} & \multicolumn{2}{c|}{$\begin{array}{c}\text { Group (2) } \\
\text { HBeAg-ve } \\
\mathrm{N}=47\end{array}$} & \multicolumn{2}{c|}{ Total } & $\begin{array}{c}\text { P. } \\
\text { Value }\end{array}$ \\
\cline { 2 - 9 } & $\mathrm{N}$ & $\%$ & $\mathrm{~N}$ & $\%$ & & \\
\hline Asymptomatic & 21 & 91 & 44 & 93.6 & 65 & 92.9 & 1.00 \\
\hline Fatigue & 1 & 4.3 & 1 & 2.1 & 2 & 2.9 & 1.00 \\
\hline Abdominal pain & 0 & 0 & 1 & 2.1 & 1 & 1.4 & 1.00 \\
\hline Jaundice + fatigue & 0 & 0 & 1 & 2.1 & 1 & 1.4 & 1.00 \\
\hline All symptoms* & 1 & 4.3 & 0 & 0 & 1 & 1.4 & 1.00 \\
\hline
\end{tabular}

* Having all symptoms of fatigue +abdominal pain +jaundice and distention *this table shows that there were no statistically significance differences in the symptoms between the studied groups.

While, in Al-Ashqar et al., from SaudiArabia ${ }^{(17)}$, only $20 \%$ of the HBeAg-+ve patients achieved undetectable HBV- DNA at 48 weeks compared to $60.7 \%$ in the HBeAgve ones ${ }^{(17)}$. The shorter follow up duration in their study compared to ours in addition to the small number of studied patients could stand behind such a difference in results. While our results coincide with data from Far east and Middle of Asia(18-22). Ting-Tsung chang and his colleagues from Taiwan, showed in their 5 year follow up study of 146 Entecavir treated patients that 94\%
(88/94) had HBV- DNA $<300$ copies/mL and $80 \%(78 / 98)$ had normalized ALT levels ${ }^{(19)}$. In addition, Mann et al reported comparable results after 3 years follow up of Europian CHB patients regarding efficacy and safety of entecavir ${ }^{(23)}$. In North America, Morris and his colleagues from Toronto-Canada, found in his study of (HBeAg)-positive, Lamivudine refractory patients that switching to Entecavir was superior to continued Lamivudine at week 48 it regards to histological improvement, viral load reduction, and ALT normalization ${ }^{(24)}$. 


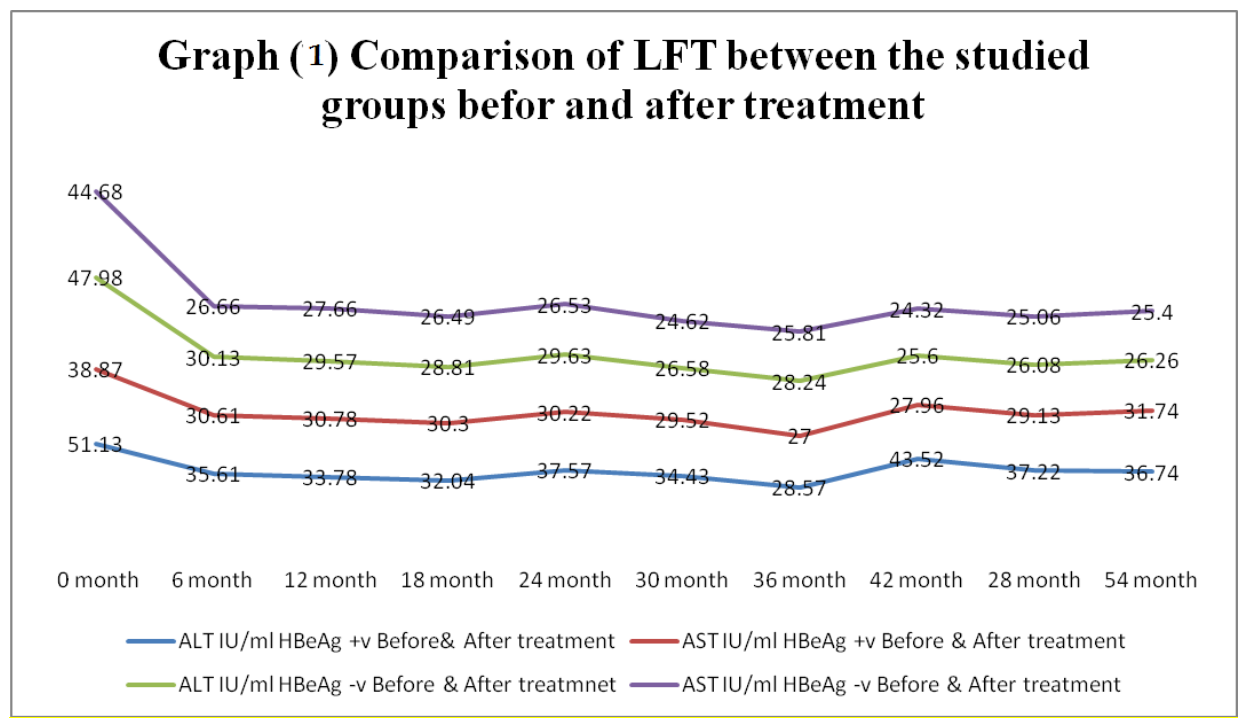

Results from South America are also comparable to our data regarding efficacy and safety of entecavir $(25,26)$. However, a similar but smaller study from Morocco, North Africa showed only $85 \%$ viral response in 48 weeks follow up of 41 patients on Entecavir therapy ${ }^{(27)}$. We presented $21.74 \% \mathrm{HBeAg}$ sero-conversion, and only $2.13 \% \mathrm{HBsAg}$ seroconversion. These findings coincide with Ting and his colleagues who $23 \%$ achieved $\mathrm{HBeAg}$ sero-conversion and $1.4 \% \mathrm{HBsAg}$ sero-conversion during the study ${ }^{(19)}$. Also similar results were shown by Cheng-Yuan Peng et al., from Taiwan ${ }^{(21)}$. In addition, they found that complete virological response at 6 month is a favorable predictive of $\mathrm{HBeAg}$ loss at 2 years of Entecavir therapy. Therefore, measurement of serum HBV-DNA level at 6 months of Entecavir therapy is optimal to predict $\mathrm{HBeAg}$ loss at 2 years of therapy in HBeAg-positive CHB patients ${ }^{(21)}$. Data from Japan, by Atsushi and his colleagues assured the antiviral potency and viral resistance rate after 4 years of continuous Entecavir treatment in patients with $\mathrm{CHB}$ infection. They reported $96 \%$ chance of undetectable HBV- DNA with similar rates of $\mathrm{HBeAg}$ sero-conversion and HBsAg loss ${ }^{(22)}$.
Multivariate analysis in our study showed that $\mathrm{HBeAg}$ status was the only independent factor affecting the suppression of viral load on Entecavir treatment $(O R=16.9$, 95\%). As we showed that the response rate was better in $\mathrm{HBeAg}$-ve patients when compared to HBeAg (+ve) patients. At the meanwhile, in univariate analysis, it was shown that 4 factors were affecting viral load suppression; Age, ALT, AST, and HBeAg-ve status. Similarly, in a Korean national study on 1009 HBV naïve patients: multivariate analysis showed that the pretreatment (HBeAg) negative status ( $p<$ 0.001 ) and lower hepatitis $B$ virus (HBV) DNA $(p<0.001)$ were the predictors of virological response ${ }^{(20)}$. Our results reported that there were no serious adverse events of Entecavir usage, which corresponds with that of Man and his colleagues; who showed that there were no serious adverse events on Entecavir treatment of naïve $\mathrm{CHB}$ patients, followed for a total of 3 years. Also, it was associated with $>90 \%$ chance of HBV- DNA clearance ${ }^{(27)}$. Jie and his colleagues, in a real life study also reported safety of Entecavir with lack of serious adverse events. 


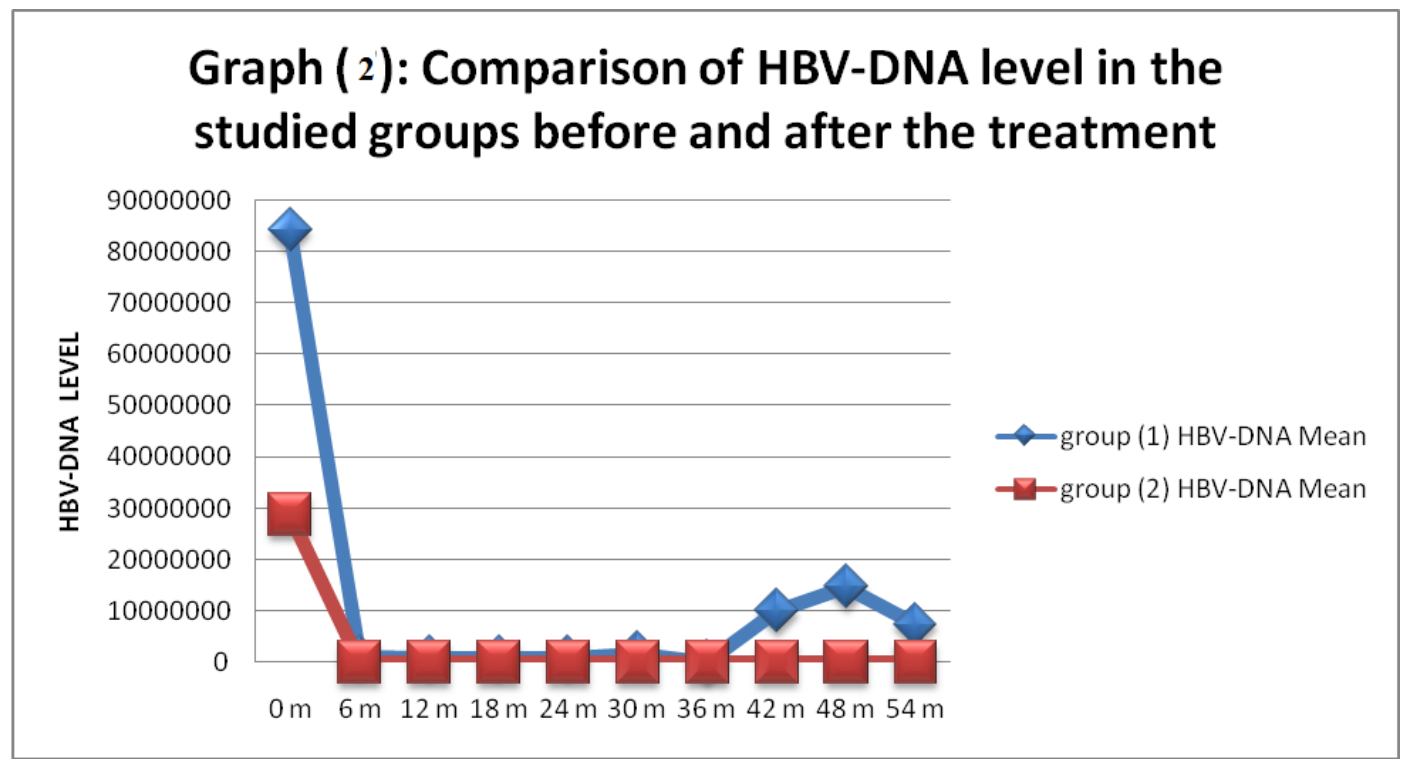

However, they described few cases of cutaneous adverse events ${ }^{(18)}$. The most frequent adverse events previously reported for Entecavir were increased ALT, upper respiratory tract infection, headache, abdominal pain, cough, pyrexia, fatigue, and diarrhea. Ting-Tsung and his colleagues also agreed with our finding regarding safety and tolerability of the drug. None of patients discontinued therapy due to adverse events. One patient experienced an ALT flare and one case of $\mathrm{HCC}^{(19)}$. Jimi and his colleagues reported a 65-year-old woman with facial granulomatous eruption. The patient is known to be HBV carrier for 35 years. Since her serum AST and ALT levels started to be elevated persistently for 3 months; she had been started on Entecavir at a dose of 0.5 $\mathrm{mg}$ daily. Two months after initiating the antiviral therapy, she presented with multiple pruritic erythematous papules and telangiectasia on the forehead, both preorbital areas and the cheeks ${ }^{(18)}$.

\section{Limitations}

The retrospective part of our study with a relatively small number of studied patients could be limitations in such a study, but being a real-life data of West Asian, with HBV genotype $D$ has its weight, adding to our daily practical knowledge and experience, and this is a lacking point in the RCT. As in the later; although valid data can be obtained, however it can't be generalized in our daily life practice.

\section{Conclusion}

As a real-life data; long term Entecavir treatment for up to 54 months in West Asian CHB patients, with genotype D suppressed HBV-DNA to an undetectable level in $100 \%$ of the HBeAg -ve, compared to $82 \%$ in the HBeAg (+ve) group. Entecavir is considered an effective and safe choice on long term use for treatment CHB patients.

\section{References}

1. Kwon $\mathrm{H}$ and Lok AS. Hepatitis B therapy. Nat Review Gastroenterol Hepatol. 2011; 8:275-84.

2. Abbas $Z$ and Siddiqui AA. Agents on clinical outcomes and hospitalization costs. World J Hepatol. 2011; 27; 3(12): 292-299.

3. Lynch P, Pittet D, Borg MA, et al. Infection control in countries with limited resources. 2007; J Hosp Infect 65 Suppl 2:148-150.

4. Ganem D, and Prince AM Hepatitis $B$ virus infection - natural history 
and clinical consequences. 2004; N Engl J Med 350: 1118-1129.

5. Bosch FX., Ribes J., Cleries R., et al. Epidemiology of hepatocellular carcinoma. Clinical Liver Disease. 2005; 9:191-211.

6. Hoofnagle JH, Doo E, Liang TJ, et al. Management of hepatitis $B$ : summary of a clinical research workshop. Hepatology 2007; 45:10561075.

7. EASL Clinical Practice Guidelines. Management of chronic hepatitis B. Journal of Hepatology 2009; 50227-242. CH 1205 Geneva, Switzerland.

8. Kim SS, Cheong JY and Cho SW. Current nucleos ( $t$ )ide analogue therapy for chronic hepatitis B. 2011; Gut Live;5:278-87.

9. Lok AS and McMahon J. AASLD practice guidelines for chronic Hepatitis B. Hepatology 2007; 45(2):507-539.

10. Rivkin A. Entecavir: a new nucleoside analogue for the treatment of chronic hepatitis B. Drugs Today (Barc) 2007; 43(4):201-20.

11. Lok AS, McMahon BJ, Brown RS Jr et al. Antiviral therapy for chronic hepatitis $B$ viral infection in adults: A systematic review and metaanalysis. Hepatology 2016; 63(1): 284-306.

12. Yuen MF, Yuan HJ, Wong DK, et al. Prognostic determinants for chronic hepatitis B in Asians: therapeutic implications. Gut 2005; 54:16101614.

13. Zhonghua Gan Zang Bing Za Zhi. Chinese Society of Hepatology and Chinese Society of Infectious Diseases, Chinese Medical Association. [The guideline of prevention and treatment for chronic hepatitis B (2010 version)] 2011; 19:13-24. Chinese.

14. Liaw YF, Leung $\mathrm{N}$, Kao JH, et al. Asian-Pacific consensus statement on the management of chronic hepatitis B: a 2012 update. Hepatol Int 2012; 6:263-283.

15. CHPA. IMS China Hospital Market Overview 2012.

16. Pol $S$ and Lampertico P. First-line treatment of chronic hepatitis B with Entecavir or tenofovir in reallife settings: from clinical trials to clinical practice $J$ Viral Hepatitis. 2012 19, 377-386.

17. Al-Ashqar HI, Al-Quaiz M, Dahab ST, et al. Entecavir for the treatment of real-life chronic hepatitis $B$ patients: a study from Saudi Arabia. Ann Saudi Med. 2013; 33(2):119-23.

18. Jimi Yoon1, Donghwa Park1 and Chiyeon Kim1. A Granulomatous Drug Eruption Induced by Entecavir Ann Dermatol 2013; 25. (4):493-495.

19. Ting TC, Ching LL, SeungKew $Y$, et al. Entecavir treatment for up to 5 years in patient with $\mathrm{HBeAg}$ positive CHB. Hepatol 2010; 51:422430.

20. Ju-Yeon C, Won S, Dong-Hyun S, et al. Long-term real-world entecavir therapy in treatment-naïve hepatitis B patients: base-line hepatitis B virus DNA and hepatitis B surface antigen levels predict virologic response. Korean J Intern Med 2016; kjim.2016.096.

21. Cheng-YP, Tsai-YH, Kuo-CT, et al. HBV-DNA level at 6 months of Entecavir treatment predicts $\mathrm{HBeAg}$ loss in HBeAg-positive chronic hepatitis B patients. Journal of the Formosan Medical Association 2013; 275:235-250.

22. Atsushi O, Fumitaka S, Yusuke K, et al. Long-term continuous Entecavir therapy in nucleos(t)ide-naïve chronic hepatitis $B$ patients. Journal of Hepatol 2012; 57:508-514.

23. Man FY, Wai KS, James F, et al. Three Years of Continuous Entecavir Therapy in Treatment-Naïve Chronic Hepatitis B Patients: viral Suppression, Viral Resistance, and Clinical Safety. The Am J of gastroenterol 2011; 106: 1264-1271. 
24. Morris S, Cihan Y, Halis Sk, et al. Entecavir Therapy for LamivudineRefractory Chronic Hepatitis B: Improved Virologic, Biochemical, and Serology Outcomes Through 96 Weeks. Hepatol 2008; 48: 1.

25. Ridruejo E, Marciano S, Galdame O, Reggiardo MV, et al. Efficacy and safety of long term entecavir in chronic hepatitis $B$ treatment naïve patients in clinical practice. Ann Hepatol. 2014; 13(3):327-36.

26. Pereira CV, Tovo CV, Grossmann TK, Mirenda H, Dal-Pupo BB, Almeida PR Efficacy of entecavir and tenofovir in chronic hepatitis B under treatment in the public health system in southern Brazil. Mem Inst Oswaldo Cruz. 2016; 111(4):252-7.

27. Chakkor A, Rouibaa, F, Elaboudi S, Aourarh A. An evaluation of entecavir treatment among nucleos(t)ide-naïve Moroccan patients with chronic hepatitis B. BMJ Open Gastro 2016; 3: e000081 doi: 10.1136/bmjgast-2016-000081 